DOI: $10.20472 / I A C .2019 .045 .038$

\title{
JERROLD RUSK
}

Rice University, United States

\section{THE EFFECT OF RESIDENCE REQUIREMENTS ON VOTING TURNOUT ,1824-1968}

\begin{abstract}
:
The author theorizes that residence requirements will increase the costs of individual participation in U.S. elections. Different stringencies in voter residency laws will lead to different vote turnout results. This hypothesis is tested using both cross-sectional and longitudinal analyses for the period 1824-1968. The hypothesis is confirmed for both the nation at large and the separate regions of the South and non-South when using state residency requirements as the explanatory factor. County residency requirements also show an effect on voter turnout but only in the South. The effect of residency requirements is demonstrated for several races (presidential, congressional, gubernatorial) and for both presidential and midterm election years The basic conclusion of this study is that residency requirements place an important barrier to voter participation and hence must be recognized as a significant part of the legal-institutional effect on voting behavior.
\end{abstract}

\section{Keywords:}

turnout, residency, region 